\title{
Dietary assessments: how to validate primary data before conclusions can be drawn
}

\author{
By Leif Hambrceus
}

\begin{abstract}
Dietary assessment methods result almost without exception in an underestimation of energy intake. Energy turnover should consequently be evaluated on the basis of studies of energy expenditure and only with exceptions on determinations of energy intake. An objective and reliable reference to validate whether obtained data from dietary assessment may be realistic or represent an underevaluation can be based on a comparison between the observed or registered energy intake and the theoretical calculations of energy turnover based on calculated BMR with the addition of a relevant PAL factor, which is based on the lifestyle including physical activity. It is not scientifically relevant to draw any conclusions regarding the relationship between the dietary intake of various nutrients and health in a long-term perspective if energy needs are not met by dietary intake according to this assessment, nota bene if body weight is maintained.
\end{abstract}

\begin{abstract}
"Although this may seem like a paradox, all exact science is dominated by the idea of approximation" (Bertrand Russell)
\end{abstract}

\section{Introduction}

In the latest edition of the FAO/WHO/ UNU recommendations for energy and protein intake (1), it was stated that energy turnover should preferably be evaluated on the basis of studies in energy expenditure and only with exceptions on determinations of energy intake. This is essentially due to the well-known fact that dietary assessment methods almost without exceptions result in an underestimation of energy intake (EI), no matter which method for dietary assessment has been used. Furthermore, energy turnover (ET) can be covered from endogenous release from energy stores, i.e. glycogen in liver and muscles and triglycerides in the adipose tissue, which calls for studies of body composition in addition to dietary

Leif Hambræus, Prof., Dept of Medical Sciences, Nutrition Unit, Faculty of Medicine, Uppsala University, Dag Hammarskjölds väg 21, SE-752 37 Uppsala, Sweden. E-mail: Leif.Hambraeus@nutrition.uu.se

This article is based on a lecture held at the conference "Dietary assessments - how can we interpret the results?" The conference was arranged by Uppsala Food and Nutrition Centre (Uppsalo Livsmedelscentrum) in Uppsala on Nov 11, 1997.

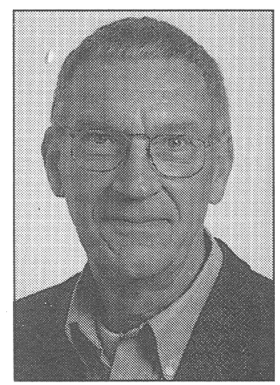

assessments for the assessment of energy turnover, while energy expenditure (EE) can be registered by direct and indirect calorimetry.

\section{Various methods}

As discussed in another paper by Lenner$n \ddot{a} s$ (2), there are several forms of methods used for studies of dietary intake, based on interviews, records, frequency questionnaire or even double portion technique. Each of them has its pros and cons. Studies of the dietary intake may furthermore be aimed at determining the nutritional status of an individual, or be used for dietary counselling or to follow up dietary treatment. However, they can also be used for research purposes in metabolic studies or for epidemiological analysis of the diethealth relationship. Finally, they can be used in order to train personnel in the evaluation of nutritional status. The goal of the study is, however, of the utmost importance when selecting the optimal method for dietary assessment. Interestingly, Goldberg and Black (1998) recently reviewed how best to analyse and interpret reported energy intake data (3).

As Beaton has so rightly stated (4) there is not and will probably never be one single golden method for estimation of the dietary intake without error. Furthermore, different types of errors have different effects on analysis and interpretation. Consequently, the selection of method for dietary assessment must firstly depend on an analysis of the aim of the study, and secondly, data collected by means of one dietary assessment aimed to study the intake of one nutrient may not necessarily be as valid for analysing the effect of another nutrient. When discussing the relevance of conclusions drawn from obtained results from studies of dietary intake, it is consequently first of relevance to analyse the primary goals of the study performed, and to what extent the method used is also optimal for any new, additional approach.

\section{Validation}

It is common that authors use various methods for dietary assessment in order to validate their findings. Thus data from frequency questionnaires in studies of larger populations have been validated by 24 hour recall interviews performed in a limited number of cases, or in some cases by means of 24 hour record methods. However, this cannot be considered an accurate form of validation as both methods may be characterised by a high risk of underestimation.

\section{Energy turnover - an objective reference}

As it can be stated that the energy equation is a first-order equation, i.e. energy $y_{\text {in }}=$ energy $_{\text {out }}$, and as the body gives priority to covering its energy needs, the dietary energy intake must cover energy needs when body weight and composition are maintained, i.e. available energy (endogenous + exogenous) must balance energy turnover and changes in energy stores.

If a person is in energy balance, which must be the case if bodyweight is stable and body composition unchanged during a certain length of time, then energy intake must balance energy turnover.

\section{Calculation of BMR}

Based on large population studies, equations have been established in order to calculate basal metabolic rate (BMR) with reasonable accuracy based on anthropo- 
metric data (weight, height, age and sex) (1). The energy turnover comprises BMR, as well as the energy needed for daily life, including characteristics of lifestyle and physical activity.

The daily activities can then be compensated for by expressing the lifestyle in relation to BMR. If various activities in daily life, as well as during various forms of physical activities, are expressed as multiples of BMR, the total energy turnover (ET) per 24 hour can be calculated based on the physical activity level (PAL) of the individual.

It has been postulated that for survival, 24 hour energy turnover represents about 1.27 times BMR, and for a sedentary lifestyle, total energy turnover represents about 1.55 times BMR. An objective and reliable evaluation whether obtained data of dietary energy intake from dietary assessment are realistic must be performed. A comparison between observed or registered energy intake (EI) and the theoretical calculations of ET based on calculated BMR with or without the addition for the lifestyle, using a relevant PAL factor, may indicate whether there might be an underevaluation (5).

Table 1 illustrates the flow sheet for estimation of energy turnover in an individual, including an example.

\section{Forms of compensation}

As studies of dietary intake result in an underevaluation, the use of various forms of compensation for energy adjustments has been proposed. However, such adjustments may involve potential serious errors per se. Firstly, differences in error structure between various nutrient vectors make energy adjustments hazardous. To what extent can we assume that the underestimation of dietary intake is the same for all nutrients? If the fat energy percentage is important, can we assume that this is the same for the missing energy units consumed but not reported? In epidemiological studies, food frequency instruments are usually used. In these studies it is quite obvious that because of differences in error structure between nutrients estimated by the same instrument (food frequency forms) the use of energy adjustments might lead to serious errors.

The underreport of energy intake was confirmed by Schoeller et al. (6) in 1990 when they analysed energy turnover by means of the doubly labelled water technique and related their findings to results obtained using dietary recall and record methods. Similar observations have been reported by Bratteby et al. (1998) in their studies on Swedish adolescents using $7 \mathrm{~d}$ dietary records (7). Sjödin et al. (8),
Table 1. How to validate dietary assessment by comparing energy intake (EI) and energy turnover (ET) with BMR, including one practical example.

Step Procedure

Example

1 Collect anthropometric data age and sex, body weight, height

Man, 25 years

Weight $76 \mathrm{~kg}$; height $180 \mathrm{~cm}$

2. Verify that body weight has not changed $=$ energy balance

3. Calculate energy intake (EI) from dietary assessment

4. Calculate BMR according to FAO/WHO/UNU 1985 equation

Stable body weight

$12,540 \mathrm{~kJ}(3,000 \mathrm{kcal})$

$7,691 \mathrm{~kJ}(1,839 \mathrm{kcal})$

$(\mathrm{kJ}): 64.4 \times 76-113.0 \times 1.8+3000$

5. Analyse physical activity from training report and lifestyle (hours of sleep, sitting, walking etc)

$\begin{array}{lll}\text { Occupation } & \text { hrs } & \text { BMR factor } \\ \text { Sleep } & 10 & 1 \\ \text { Moderate training } & 4 & 8 \\ \text { Sitting, reading, TV } & 6 & 1.3 \\ \text { Walking } & 1 & 2,5 \\ \text { Miscellaneous } & 3 & 2.5 \\ \text { ET }=19,160 \mathrm{~kJ}(4,580 \mathrm{kcal})\end{array}$

6. Calculate total energy turnover (ET) using BMR factors (see step 5)

7. Calculate PAL factor (ET/BMR)

$\mathrm{PAL}=2.5$

8. Compare estimated EI from dietary assessment $(12,540 \mathrm{~kJ})$ with

a. estimated BMR $(7691 \mathrm{~kJ})$

b. estimated ET from theoretical

calculations of BMR and PAL

$\mathrm{EI} / \mathrm{BMR}=1.6$

$\mathrm{EI} /(\mathrm{BMR} \times \mathrm{PAL})=0.76$

Comments: This example illustrates that if the dietary assessment is right, there is no room for physical training, as the EI/BMR-ratio is 1.6, e.g. only covers the normal energy turnover in an individual with a sedentary lifestyle. This is quite different from his PAL, according to lifestyle and training record (2.5).

however, showed that it is possible to obtain congruence in estimating energy turnover from dietary assessments using dietary records and doubly labelled water technique at high energy turnover. He compared data from the doubly labelled water technique with those obtained in skilled dieticians using dietary records over a 7-day period in top athletes. However, he was also able to show that each individual had almost the same dietary intake per day, while the physical activity, expressed as training time, varied considerably from day to day. Thus there was no congruence between the dietary intake and physical exercise for shorter periods, i.e. 24 h. Branth and his collaborators (9) studied energy turnover in crew members participating in an offshore sailing race. Using food inventories before and after a 25-day-sailing period, in combination with measurements of changes in body composition data to evaluate endogenous energy release, they showed that energy turnover could be calculated with accuracy, when related to data by means of doubly labelled water technique (Table 2).

\section{The risk of computerised statistical analyses}

There is a risk of forgetting the validity of primary data and the physiological significance of the findings when computerised statistical analyses are performed. The present interest in the evaluation of diethealth relationship, based on epidemiological studies using modern and advanced statistical methods in computers, has resulted in a number of statements, the significance of which can be questioned.

Furthermore, it is unfortunately often forgotten that epidemiological analysis can only be used to formulate hypotheses and not for qualitative or quantitative analysis of diet-health relationship. It should also be remembered that before any evaluation of dietary data can be performed to find any causal explanation for diet-health relationship using any statistical or epidemiological method, the basic physiological relevance of the primary data must first be assessed. Thus data from any dietary assessment, which does not cover the minimal energy requirement 
Table 2. Result from estimations of energy turnover in 6 crew members during offshore racing using anthropometric data, food inventories and doubly labelled water (7), the values refer to $\mathrm{MJ}$ per 24 hour.

\begin{tabular}{|c|c|c|c|c|}
\hline \multirow{2}{*}{$\begin{array}{l}\text { Subject } \\
\text { No }\end{array}$} & \multicolumn{2}{|c|}{ Energy intake } & \multirow{2}{*}{$\begin{array}{c}\text { Endogenous } \\
\text { energy } \\
\text { Release }^{c}\end{array}$} & \multirow{2}{*}{$\begin{array}{c}\text { Total energy } \\
\text { turnover }\end{array}$} \\
\hline & Mean $^{\mathrm{a}}$ & Adjusted $^{\mathrm{b}}$ & & \\
\hline 1 & 16.9 & 15.6 & 5.2 & 20.8 \\
\hline 2 & 16.9 & 20.9 & - & 20.9 \\
\hline 3 & 16.9 & 16.4 & 3.4 & 19.8 \\
\hline 4 & 16.9 & 17.5 & 1.8 & 19.3 \\
\hline 5 & 16.9 & 15.5 & 1.8 & 17.3 \\
\hline 6 & 16.9 & 13.2 & 4.7 & 17.9 \\
\hline Mean & 16.9 & 16.5 & 2.8 & 19.3 \\
\hline
\end{tabular}

\footnotetext{
a based on food inventories

(total consumption divided by number of crew members)

b based on total energy turnover minus endogenous energy released

c based on estimations of changes in body composition

d based on determinations by the doubly labelled water technique
}

based on BMR and a suitable PAL-factor, cannot be considered to be accurate for epidemiological analysis of relationship between dietary intake and health. It is thus recommended that validation measures, consisting of calculated EI/BMR ratios, should be included in dietary surveys (5).

If the data are considered as representative in a long-term perspective, energy balance must have been obtained, i.e. if the data do not cover minimal energy need for sedentary life (BMR x 1.55) they must represent an underestimation. It is then necessary to find out whether the missing energy units are covered from a qualitatively identical diet or whether other sources of energy have been consumed and not recorded. It is then self-explanatory that no conclusions can be drawn regarding the relation between fat intake and health parameters, as long as it is not known from where the missing energy

\section{References}

1. FAO/WHO/UNU Expert Consultation: Energy and protein requirements. WHO Techn Rep Ser 724, WHO, Geneve 1985.

2. Lennernäs M: Dietary assessment and validity: to measure what is meant to measure. Scand $\mathrm{J}$ Nutr/Näringsforskning 1998;42:63-5.

3. Goldberg GR, Black AE: Assessment of the validity of reported energy intakes - review and recent developments. Scand J Nutr/Näringsforskning 1998;42:6-9

4. Beaton GH, Burema J, Ritenbaugh C: Errors in the interpretation of dietary assessments. Am J Clin Nutr 1997; 65 (suppl): 1100S-1107S.

5. Black AE, Bingham SA, Johansson $G$, Coward WA: Validation of dietary intakes of protein and energy against 24 hour urinary $\mathrm{N}$ and DLW energy expenditure in middle-aged women, retired men units in the dietary intake are coming. Interestingly, this has not made the authors hesitate to draw conclusions in such classical studies as those from the Framingham study (10).

In a study of the dietary energy intake in 2,500 individuals (mean age around 55 years) they reported $2,150 \mathrm{kcal}$ in men and $1,580 \mathrm{kcal}$ in females. If these data were to be related to a calculated BMR based on $70 \mathrm{~kg}$ bodyweight in male and $60 \mathrm{~kg}$ bodyweight in females, the BMR factor would be 1.2 to 1.3 , which indicates that there must have been an underestimation, as the BMR factor for a sedentary normal population is given as 1.55 , but usually is found to be between 1.6 and 1.8 in a normal population (5).

Recently published epidemiological studies on the relation between fat intake and breast cancer (11) have been based on food frequency studies where the mean energy intake also corresponded to a BMR factor of less than 1.3

Studies of the relation between calcium intake and osteoporosis (12) were based on food frequency in which the reported energy intake was only equivalent to or lower than the expected BMR in the actual age group. This must mean 30 to $50 \%$ underestimation. If individuals do not lose body weight for a substantial number of months, it may be questioned whether it is possible to draw any conclusions regarding the relation between the intake of certain nutrients and the health panorama without knowing the composition of the "missing" energy units. In addition, it could be questioned to what extent food frequency studies during the last year can be considered to be representative of food habits during the last 2-3 decades, which is a must if long-term relationship between dietary habits and health panorama is to be considered.

\section{Conclusions}

Nutrition science is hampered by the fact that there is a questionable precision in most methods for dietary assessments. The theoretical calculations on BMR in combination with the use of PAL-factor as indicator of energy turnover, however, seem to represent surprisingly well reliable data, although there is still some risk of underevaluation of energy turnover even using these calculations. This, in addition to the fact that the body gives priority to cover energy needs and that there must be a balance between energy intake, energy turnover and energy stores, makes prediction of the EI/BMR ratio a suitable way to validate food consumption data. In case energy needs are not met by dietary intake according to this assessment, and body weight is maintained, it is not scientifically relevant to draw any conclusions regarding the relationship between the dietary intake of various nutrients and health in a long-term perspective. and post-obese subjects: comparisons with validation against presumed energy requirements. Eur J Clin Nutr 1997;51:405-13.

6. Schoeller DA: How accurate is self-reported energy intake? Nutr Rev 1990;48:373-9.

7. Bratteby L-E, Sandhagen B, Fan H, Samuelson G: Total energy expenditure and physical activity as assessed by the doubly labeled water method in Swedish adolescents in whom energy intake was underestimated by 7-d diet records. Am J Clin Nutr 1998;67:905-11.

8. Sjödin A, Andersson A, Högberg J, Westerterp $\mathrm{K}$ : Energy balance in cross-country skiers: a study using doubly labeled water. Med Sci Sports Exerc 1994;24:720-4.

9. Branth S, Hambraeus L, Westerterp K, Andersson A, Edsgren R, Mustelin M, Nilsson R:
Energy turnover in a sailing crew during offshore racing around the world. Med Sci Sports Exerc 1996;28:1272-6.

10. Millen BE, Quatronomi PA, Franz MM, Epstein BE, Cupples LA, Copenhafer DL: Population nutrient intake approaches dietary recommendations: 1991 to 1995 Framingham Nutrition Studies. J Am Diet Assoc 1997;97:742-9.

11. Wolk A, Bergström R, Hunter D, Willett W, Lung $H$, Holmberg L, Bergkvist L, Bruce A, Adami H-O: A prospective study of association of monounsaturated fat and other types of fat with risk of breast cancer. Arch Intern Med 1998;158:41-5.

12. Michaëlsson K, Holmberg L, Mallmin H, Wolk A, Bergström R, Ljunghall S: Diet, bone mass and osteocalcin. A cross-sectional study. Calcif Tissue Int 1995;57:86-93. 